$$
\text { NGUYẼ̃N HẢI TRƯỜNG }
$$

\title{
ĐÁNH GIÁ KHẢ NĂNG TRẢ NỢ VÀ PHÂN LOẠI KHÁCH HÀNG VAY TÍN CHẤP TẠI NGÂN HÀNG THƯỚNG MẠI CỔ PHẦN VIẸTT NAM THỊNH VƯợNG
}

2017

TRUOÒNG ĐẠI HOC KINH TÉ QUỐC DÂN 


\title{
TRƯờNG ĐẠI HỌC KINH TẾ QUỐC DÂN
}

NGUYẼ̃N HẢI TRƯờNG

\author{
ĐÁNH GIÁ KHẢ NĂNG TRẢ NỢ VÀ PHÂN LOẠI \\ KHÁCH HÀNG VAY TÍN CHẤP TẠI NGÂN HÀNG \\ THƯƠNG MẠI CỔ PHẦN VIỆT NAM THỊNH VƯợNG
}

Chuyên ngành: Điều khiển học kinh tế

\section{TÓM TÁ́T LUẬN VĂN}

\author{
HÀ NộI - 2017
}




\section{TÓM TÁ́T LUẬN VĂN}

Trong các hoạt động kinh doanh của NHTM, hoạt động tín dụng chiếm tỷ trọng lớn nhất và đóng góp phần lớn vào tổng lợi nhuận của ngân hàng.Đồng thời,hoạt động tín dụng cũng là hoạt động tiềm ẩn rất nhiều rủi ro cho ngân hàng khi khách hàng không đủ khả năng hoặc không thực hiện đầy đủ nghĩa vụ trả nợ đối với ngân hàng. Rủi ro tín dụng đầu tiên ảnh hưởng trực tiếp đến ngân hàng cho vay, sau đó sẽ đến các ngân hàng hoặc các bên có liên quan, và lan rộng hơn còn có thể ảnh hưởng xấu đến toàn bộ nền kinh tế, đặc biệt đối với nền kinh tế đang phát triển tại Việt Nam. Nhóm sản phẩm tín dụng bao gồm sản phẩm cho vay có tài sản đảm bảo (thế chấp) và sản phẩm cho vay không tài sản đảm bảo (tín chấp), trong đó sản phẩm cho vay tín chấp dành cho khách hàng cá nhân hiện đang là sản phẩm rất phổ biến trên thị trường và đang được các ngân hàng TMCP chú trọng phát triển nhằm phục vụ mọi đối tượng khách hàng, từ những người có nguồn thu qua thẻ, tiền mặt đến các hộ kinh doanh với mục đích vay đa dạng như: mua sắm nội thất, mua xe, cưới hỏi, du học, mở rộng sản xuất kinh doanh...Do tính chất của sản phẩm khách hàng vay không cần thế chấp tài sản và số tiền vay tối đa có thể lên đến 500 triệu đồng, nên sản phẩm này tiềm ẩn rất nhiều rủi ro đối với ngân hàng khi khách hàng không đủ khả năng hoặc không thực hiện đầy đủ nghĩa vụ trả nợ.

Đề tài: "Đánh giá khả năng trả nợ và phân loại khách hàng vay tín chấp tại Ngân hàng TMCP Việt Nam Thịnh Vượng (VPBank)" được thực hiện nhằm xác định những yếu tố nào ảnh hưởng tới khả năng trả nợ (xác suất có nợ quá hạn) của khách hàng vay tín chấp, để sau đó có thể phân loại khách hàng ("tốt" - không có nợ quá hạn, "xấu" - có nợ quá hạn). Những kết quả thu được từ nghiên cứu này sẽ là cơ sở để hỗ trợ ngân hàng ra quyết định nên cho vay hay không, nếu cho vay thì 
cho vay với lãi suất ưu đãi hay lãi suất thường đối với những khách hàng mới. Còn đối với những khách hàng hiện hữu, việc đánh giá được khả năng trả nợ của khách hàng sẽ giúp cho ngân hàng có thể nhận diện được những khách hàng "xấu" (khả năng cao có nợ quá hạn), từ đó đưa ra những biện pháp xử lý để hạn chế rủi ro từ những khoản vay của những khách hàng này.

Dựa trên những nghiên cứu trước đây về việc tại sao người ta mất khả năng chi trả các khoản nợ với ngân hàng như Livingston và Lunt (1992), Lea (1993), Cox và Jappelli (1993), Duca and Rosenthal (1993), Black and Morgan (1998), Crook (2001), Vương Quân Hoàng (2006), mô hình chấm điểm tín dụng của FICO, hệ thống xếp hạng tín dụng cá nhân của BIDV, Vietinbank, Erst\& Young, cùng với việc nghiên cứu và phân tích dữ liệu khách hàng vay tín chấp tại VPBank, tác giả đề xuất mô hình nghiên cứu bao gồm 11 yếu tố ảnh hướng tới khả năng trả nợ của khách hàng vay tín chấp, bao gồm: độ tuổi, giới tính, tình trạng hôn nhân, trình độ học vấn, chức vụ công tác, thu nhập hàng tháng của khách hàng, số sản phẩm khách hàng nắm giữ, thời hạn cho vay, thời gian còn lại khoản vay, lãi suất cho vay và dư nợ gốc còn lại của khoản vay. Trong nghiên cứu này, tác giả sử dụng kết hợp hai phương pháp nghiên cứu là nghiên cứu định tính và nghiên cứu định lượng. Nghiên cứu định tính dùng để xử lý và làm sạch dữ liệu. Nghiên cứu định lượng dùng để xây dựng mô hình dự báo và đánh giá chất lượng mô hình.

Nghiên cứu định lượng được thực hiện bằng việc sử dụng dữ liệu thứ cấp lấy từ hệ thống T24bao gồm thông tin của 45,876 khoản vay tín chấp của khách hàng cá nhân tại VPBank chốt đến thời điểm 31/12/2016. Sau khi xử lý và làm sạch dữ liệu, tác giả sử dụng phân tích thống kê mô tả để tìm hiểu mối quan hệ giữa các biến trong mô hình. Theo kiểm định t-test kết quả cho thấy có sự khác biệt giữa độ tuổi, thu nhập hàng tháng, thời gian và lãi suất vay của hai nhóm khách hàng có và không có nợ quá hạn, trong khi đó không có sự khác biệt giữa thời gian còn lại 
khoản vay, dư nợ gốc của hai nhóm khách hàng này. Theo kiểm định Pearson's Chi-squared kết quả cho thấy với mức ý nghĩa trên $99 \%$ các biến rời rạc như giới tính, tình trạng hôn nhân, trình độ học vấn và chức vụ công tác của khách hàng đều có mối quan hệ với biến nợ quá hạn (biến đầu ra của mô hình). Vì vậy, có thể đưa các biến này vào để xây dựng mô hình dự báo. Mô hình sử dụng để xây dựng mô hình dự báo là mô hình hồi quy Logistic. Ban đầu ta chia tập dữ liệu làm hai phần: dữ liệu huấn luyện (training data) và dữ liệu kiểm tra (testing data) bằng phương pháp lấy mẫu ngẫu nhiên không hoàn lại. Dữ liệu huấn luyện chiếm $70 \%$ tổng quan sát, còn dữ liệu kiểm tra bao gồm $30 \%$ số quan sát còn lại. Dữ liệu huấn luyện được sử dụng để xây dựng mô hình dự báo, còn dữ liệu kiểm tra được sử dụng để dự báo xác suất khách hàng có nợ quá hạn (tức quá hạn từ 10 ngày trở lên theo định nghĩa của NHNN), từ đó phân loại khách hàng ("tốt" - không có nợ quá hạn, "xấu" - có nợ quá hạn) trên tập dữ liệu kiểm tra dựa vào giá trị ngưỡng xác suất 0.5 , nghĩa là nếu xác suất khách hàng có nợ quá hạn lớn hơn 0.5 thì khách hàng đó được gọi là khách hàng "xấu”, ngược lại, nếu xác suất khách hàng có nợ quá hạn không lớn hơn 0.5 thì khách hàng đó được gọi là khách hàng "tốt". Sau đó tác giả so sánh kết quả phân loại khách hàng theo mô hình dự báo và nhóm khách hàng thực tế trên dữ liệu kiểm tra để từ đó đánh giá được chất lượng mô hình dự báo.

Kết quả mô hình hồi quy Logisticdựa trên dữ liệu huấn luyện cho thấy với mức ý nghĩa trên $99 \%$ tất cả 11 yếu tố đã đề cập ở trên đều ảnh hướng đến khả năng có nợ quá hạn của khách hàng vay tín chấp, bao gồm: độ tuổi, giới tính, tình trạng hôn nhân, trình độ học vấn, chức vụ công tác, thu nhập hàng tháng của khách hàng, số sản phẩm khách hàng nắm giữ, thời hạn cho vay, thời gian còn lại khoản vay, lãi suất cho vay và dư nợ gốc còn lại của khoản vay. Trong quá trình xây dựng mô hình tác giả đã xử lý những vấn đề về dữ liệu không cân bằng (imbalanced data), độ tương quan giữa các biến, vấn đề đa cộng tuyến và loại bỏ các biến không có ý nghĩa thống kê thông qua việc sử dụng các hàm trong phần mềm phân tích $\mathrm{R}$ 
(phần mềm sử dụng trong đề tài nghiên cứu). Kết quả đánh giá chất lượng mô hình trên dữ liệu kiểm tra cho thấy $\mathrm{AUC}=0.76$ (chất lượng dự báo khá), tỷ lệ dự báo đúng các khoản vay có nợ quá hạn trong thực tế là 73\% (tức trong 100 khoản vay có nợ quá hạn trong thực tế thì mô hình dự báo chính xác được 73 khoản vay).

Kết quả nghiên cứu và mô hình dự báo trên có thể giúp ngân hàng trong việc đánh giá khả năng trả nợ của khách hàng vay tín chấp (khả năng có nợ quá hạn của khách hàng) đối với những khách hàng hiện hữu cũng như khách hàng mới, phân loại khách hàng "tốt"' "xấu" để từ đó đưa ra những biện pháp, chính sách phù hợp với từng đối tượng khách hàng nhằm giảm thiểu rủi ro đối với những khoản vay tín chấp vốn dĩ đã tiềm ẩn rất nhiều rủi ro khi khách hàng vay không cần thế chấp tài sản.

So với những nghiên cứu trước đây, những điểm đóng góp mới trong nghiên cứu này của tác giả bao gồm: đối tượng nghiên cứu mới (khách hàng cá nhân vay tín chấp); dữ liệu lớn với 45,876 mẫu quan sát và đáng tin cậy (dữ liệu thu thập từ hệ thống ngân hàng lõi); đề cập đến vấn đề dữ liệu không cân bằng (imbalanced data) - vấn đề thường gặp trong thực tế đối với những bài toán trong ngân hàng như: dự báo thẻ đóng, dự báo khoản vay có nợ quá hạn, có nợ xấu... Trong đề tài nghiên cứu của tác giả, bài toán được đặt ra là dự báo khoản vay có nợ quá hạn (quá hạn từ 10 ngày trở lên). Số khoản vay có nợ quá hạn chỉ chiếm khoảng 5\% trên tổng số khoản vay, vì vậy, sẽ rất khó để xây dựng được mô hình dự báo với độ chính xác cao nếu như chúng ta không xử lý vấn đề dữ liệu không cân bằng nêu trên. Trong đề tài nghiên cứu để xử lý vấn đề dữ liệu không cân bằng trên tập dữ liệu huấn luyện tác giả sử dụng phương pháp "oversampling” (sao chép ngẫu nhiên có hoàn lại các khoản vay có nợ quá hạn sao cho số khoản vay có nợ quá hạn bằng với số khoản vay không có nợ quá hạn), đây là một trong những phương pháp "resampling" (lấy mẫu lại). Kết quả đánh giá chất lượng dự báo trên tập dữ liệu 
kiểm tra dựa vào chỉ số AUC cho thấy: AUC khi chưa xử lý dữ liệu không cân bằng chỉ có 0.6 - chất lượng dự báo rất kém, trong khi AUC khi đã sử dụng phương pháp "oversampling” để xử lý dữ liệu không cân bằng là 0.76 - chất lượng dự báo khá. Ngoài ra, do dữ liệu ngân hàng là rất lớn và trong quá trình nhập liệu thường có những sai sót hoặc dữ liệu không đẩy đủ xuất phát từ lỗi của chuyên viên nhập liệu hoặc từ hệ thống, nên dữ liệu thường chưa được làm sạch. Việc xử lý và làm sạch dữ liệu mất rất nhiều thời gian và công sức. Hạn chế của đề tài nghiên cứu là việc sử dụng mô hình hồi quy Logistic để dự báo các khoản vay có nợ quá hạn chưa đem lại độ chính xác thực sự cao do vấn đề dữ liệu không cân bằng. Trong tương lai, sẽ cần nhữngmô hình cao cấp hơn để cải thiện chất lượng dự báo đối với những bài toán dữ liệu không cân bằng nêu trên như mô hình cây quyết định hay mô hình cây kết hợp. 


\section{Tài liệu tham khảo}

Black, S. E., \& Morgan, D. P. (1998). Risk and the democratization of credit cards. Working Paper, Federal Reserve Bank of New York (June).

Cox, D., \& Jappelli, T. (1993). Credit rationing and private transfers: Evidence from survey data. The Review of Economics and Statistics, 72(3), 445-454.

Crook, C. (2001). The social character of knowing and learning: implications of cultural psychology for educational technology. Journal of Information Techology for Teacher Education, 10(1-2), 19-36.

Duca, J. V., \& Rosenthal, S. S. (1994). Borrowing constraints and access to owneroccupied housing. Regional Science and Urban Economics, 24(3), 301-322.

Hoàng, V. Q., Hưng, Đ. G., Hữu, N. V., \& Ngọc, T. M. (2006). Phương pháp thống kê xây dựng mô hình định mức tín nhiệm khách hàng thể nhân. Vietnam Journal of Mathematical Applications, 4(2), 1-16.

Livingstone, S. M., \& Lunt, P. K. (1992). Predicting personal debt and debt repayment: Psychological, social, and economic determinants. Journal of Economic Psychology, 13, 111-134.

Webley, P., \& Lea, S. E. (1993). Towards a more realistic psychology of economic socialization. Journal of Economic Psychology, 14(3), 461-472. 